EXPERIMENTAL STUDY

\title{
Postnatal endotoxin exposure results in increased insulin sensitivity and altered activity of neuroendocrine axes in adult female rats
}

\author{
Cecilia Nilsson ${ }^{1,4}$, Eva Jennische ${ }^{2}$, Hoi-Por Ho ${ }^{3}$, Elias Eriksson ${ }^{3}$, Per Björntorp ${ }^{1,4}$ and Agneta Holmäng ${ }^{1,4}$ \\ Departments of ${ }^{1}$ Heart and Lung Diseases, ${ }^{2}$ Histology, ${ }^{3}$ Pharmacology and ${ }^{4}$ The Wallenberg Laboratory, Göteborg University, Göteborg, Sweden
}

(Correspondence should be addressed to C Nilsson, Wallenberg Laboratory, Göteborg University, S-413 45 Göteborg, Sweden;

Email: Cecilia.Nilsson@wlab.wall.gu.se)

\begin{abstract}
Objectives: Severe postnatal infection leads to a systemic inflammatory response with release of cytokines and glucocorticoids, representing a stressful event for the newborn child. The purpose of this study was to mimic this situation and to study the effects of early postnatal endotoxin exposure of female rat pups on metabolic, endocrine and anthropometric variables in adulthood.

Design: Female pups were given subcutaneous injections of lipopolysaccharides (LPS; Salmonella enteriditis, $0.05 \mathrm{mg} / \mathrm{kg}$ ) or vehicle 3 and 5 days after birth.

Results: Six hours after injection, LPS-treated rats had higher corticosterone levels than controls. As adults, LPS-exposed female rats showed increased insulin sensitivity $(P<0.05)$, measured with the hyperinsulinemic euglycemic clamp ( $5 \mathrm{mU} / \mathrm{kg}$ per $\mathrm{min}$ ). They exhibited a higher locomotor activity $(P<0.05)$ and increased skeletal muscle mass in comparison with controls $(P<0.05)$. Basal ACTH and corticosterone levels in LPS-treated rats were elevated $(P<0.05)$, as were corticosterone levels after exposure to a novel environment stress $(P<0.05)$. The adrenals were morphologically changed and enlarged $(P<0.05)$ in LPS-exposed rats at 11 weeks of age, and a higher density of hypothalamic but not hippocampal glucocorticoid receptor protein was found in the LPS-treated rats $(P<0.05)$. Furthermore, circulating progesterone levels were lower $(P<0.05)$ and testosterone tended to be higher.

Conclusion: The results indicate that postnatal exposure to LPS leads to increased insulin sensitivity in the adult female rat. In addition, LPS-treated rats showed changes in the regulation of hypothalamicpituitary-adrenal and hypothalamic-pituitary-gonadal axes. This study suggests that postnatal exposure to an endotoxin such as LPS can induce specific programming of neuroendocrine regulation, with long-term consequences in adult life.
\end{abstract}

European Journal of Endocrinology 146 251-260

\section{Introduction}

Recent epidemiological evidence suggests that influences during the perinatal period may be important in determining the susceptibility to disease later in life. In humans, reduced fetal growth and low birth weight are statistically related to visceral obesity, insulin resistance and hypertension in adulthood $(1,2)$.

In rats, the early postnatal period is characterized by extensive brain development (3). The stress hyporesponsive period begins on day 2 of life and continues into week 2 of life. It is characterized by low circulating levels of glucocorticoids and a hyporesponsivity of the hypothalamic-pituitary-adrenal (HPA) axis to several stimuli (4). The rationale for the stress hyporesponsiveness seems to be to avoid fluctuations in corticosterone levels during a period when brain development occurs. Sustained elevation in or removal of glucocorticoids in the early postnatal period results in permanent effects on brain development (5-7).

During this period, environmental events are known to alter the development of the HPA axis $(3,8)$. Neonatal handling leads to adult animals exhibiting an attenuated HPA axis response to stress and an increased density of glucocorticoid receptors (GR) in the hippocampus and frontal cortex (8). On the contrary, repeated maternal separation results in an increased HPA axis response to stress (9).

The endocrine and immune systems are closely interconnected and mutually regulated. In the developing rat, endotoxin elicits both acute-phase and inflammatory responses, stimulating the HPA axis, with a 
concomitant increase in glucocorticoid secretion (10). Several studies have shown that a postnatal endotoxin challenge results in long-term disturbances of the HPA axis function, with an increase in basal corticosterone pulse frequency and pulse amplitude, and increased stress responsivity $(11,12)$.

In adult humans, neuroendocrine abnormalities, such as a hyperactivity of the HPA axis, are often associated with abdominal obesity. Such neuroendocrine abnormalities may induce the insulin resistance, dyslipidemia and hypertension seen in patients with the metabolic syndrome (13). Previous studies from our group have shown that prenatal immune challenges by endotoxin or cytokines can permanently program the HPA and hypothalamic-pituitary-gonadal (HPG) axes to altered sensitivity in the adult offspring. This is, in the adult rat, accompanied by metabolic disturbances such as obesity and insulin resistance (14, 15).

With this background, the purpose of this study was to examine whether postnatal endotoxin exposure in female pups causes long-lasting effects on endocrine, metabolic and anthropometric variables in the adult rat.

\section{Materials and methods}

\section{Animals}

Pregnant nulliparous Wistar rats were purchased from B\&K Universal (Sollentuna, Sweden) and were housed singly under controlled conditions (temperature 21$22^{\circ} \mathrm{C}$, humidity 55-65\%, lights on from 0700 to $1900 \mathrm{~h})$ until parturition. Before the first injection, pups were randomly distributed among mothers, so that each mother had the same number of pups (seven to nine pups per dam and the same ratio of male to female pups). Each nest contained only pups receiving the same treatment. Pups were raised with a lactating mother until 4 weeks of age, and then placed in cages housing two to four animals. Male pups were removed and, for this study, only female pups were used. All were fed with commercial rat chow, containing $18.7 \%$ protein, $4.7 \%$ fat and $63 \%$ carbohydrates with a sufficient supply of vitamins and minerals (B\&K Universal), and were provided with tap water available ad libitum. The study was approved by the Animal Ethics Committee of Göteborg University.

\section{Study procedure}

On days 3 and 5 after birth, pups were injected s.c. with $0.05 \mathrm{mg} / \mathrm{kg}$ bacterial endotoxin (lipopolysaccharides (LPS)), a dose known to provoke HPA axis activation, but no fatalities $(10,11)$. LPS (Salmonella enteriditis; Sigma Chemical Co., St Louis, MO, USA) was dissolved in $0.1 \mathrm{ml}$ sterile saline. Control pups received only sterile saline. At $30 \mathrm{~min}$ and $6 \mathrm{~h}$ after the first injection, five pups from each group were decapitated and blood was collected for corticosterone analysis. Pups were weaned at 4 weeks of age. The rats were weighed once weekly from 5 weeks of age. Blood samples were collected from a nick in the tail after fasting overnight, for determinations of insulin (week 7), adrenocorticotropin (ACTH) (week 8) and, upon sexual maturity, testosterone, progesterone and 17 $\beta$-estradiol (week 9).

\section{Vaginal smear}

Vaginal smears were obtained daily during 10 consecutive days when the rats were 8-9 weeks old to determine the estrous cycle (16). A cycle is divided into four stages: estrus, diestrus 1, diestrus 2 and proestrus. The usual duration of a cycle in rats is about 4 days. In this study, all rats exhibited normal cyclicity with clear ovulation (measured as a characteristic, rich amount of epithelial cells without leukocytes in the smears). Blood samples for determination of sex hormones were taken the day after estrus.

\section{Locomotion}

Locomotor activity in a novel environment (exploratory behavior) was assessed in adult animals (17). This was performed by means of electronic activity meters (Digiscan activity monitor RXYZM (16) TAO; Omnitech Electronics Inc., Columbus, OH, USA), in eight soundproof, ventilated, square plexiglass cages with a floor area of $415 \times 415 \mathrm{~mm}$. Activity recording was obtained by means of three separate rows of 16 photo sensors. The photo sensor signals were continuously collected by a Digiscan analyzer and processed by a Macintosh Computer. Locomotor activity during 60 min was registered in dim light as the breaking of a sequence of beams, representing movement in a single direction. The time of day (between 1200 and 1500 h) was standardized for all groups.

\section{Stress test procedure}

In 5-week-old rats, the corticosterone response to stress was tested. This was done with a novel environment stress' test according to a modified protocol described previously (18). All tests started at $0700 \mathrm{~h}$, taking great care to keep the rats undisturbed; they were fed the night before the experiment. Tail blood was collected by a nick in the tail immediately before the test, for estimation of pre-stress levels of corticosterone $(30 \mu \mathrm{l})$. The rats were then transferred singly to a 'novel environment' (new cages, laboratory room, loud background, bright light). Blood for corticosterone determination $(30 \mu \mathrm{l})$ was taken from the tail 15,30 , 60 and $90 \mathrm{~min}$ after exposure to the novel environment. 


\section{Hemodynamic measurements}

Systemic arterial pressure and heart rate were measured in conscious rats at 9 weeks of age. This was done by a tail cuff method using equipment with a light-emitting diode and a photoresistor connected to a dual-channel recorder. Rats were warmed at $38^{\circ} \mathrm{C}$ for $10 \mathrm{~min}$ and three stable consecutive measurements were averaged. This method has been shown to give results similar to those of direct arterial cannulation (19).

\section{Euglycemic hyperinsulinemic clamp $(5 \mathrm{mU} / \mathrm{kg}$ per min)}

For estimation of insulin sensitivity, 11-week-old rats were subjected to a euglycemic hyperinsulinemic clamp as described previously (20). The animals were anesthetized with $125 \mathrm{mg} / \mathrm{kg}$ body weight thiobutabarbitural sodium (Inactin; RBI, Natick, MA, USA). Catheters were then inserted into the left carotid artery for blood sampling and into the right jugular vein for infusion of glucose and insulin. The body temperature was maintained at $37^{\circ} \mathrm{C}$ with a heating blanket. After a bolus injection, insulin $(100 \mathrm{U} / \mathrm{ml}$, human Actrapid; Novo, Copenhagen, Denmark) was continuously infused at a rate of $5 \mathrm{mU} / \mathrm{kg}$ per min. A $10 \%$ glucose solution in physiological saline was administered to maintain plasma glucose concentration at $7 \mathrm{mmol} / \mathrm{l}$. Glucose was infused at a speed guided by glucose concentration measurements in $30 \mu \mathrm{l}$ blood at regular intervals (every $5 \mathrm{~min}$ during the first $40 \mathrm{~min}$ and every $10 \mathrm{~min}$ thereafter). At 0, 40, 80, 120, 160 and $200 \mathrm{~min}$ of infusion, $250 \mu \mathrm{l}$ blood samples were taken for determination of insulin concentration. A total of $<2 \mathrm{ml}$ blood was used for the determinations, and compensated for by the infusion volumes. During the clamp, one LPS-treated rat died.

\section{Tissues}

At the completion of the clamp, the rats were killed with an intravenous injection of $\mathrm{KCl}$. The brain was quickly removed, and the hippocampus and hypothalamus dissected, snap-frozen in liquid nitrogen and stored at $-80^{\circ} \mathrm{C}$. The adrenals, thymus, heart, spleen, muscles of the hind limb - extensor digitorum longus, tibialis anterior and soleus - and the parametrial, mesenteric and retroperitoneal adipose tissues were rapidly excised and weighed.

\section{Preparation of protein extracts}

Frozen hippocampus and hypothalamus from each animal were placed into an ultracentrifuge Eppendorf tube containing 5 vol. ice-cold TEGMD buffer (20 mmol/l Tris, $1 \mathrm{mmol} / \mathrm{l}$ EDTA, $10 \mathrm{mmol} / \mathrm{l}$ sodium molybdate, $10 \%$ glycerol and $1 \mathrm{mmol} / \mathrm{l}$ dithiothreitol) with protease inhibitors. Tissue and cells were disrupted with a Soniprep 150 ultrasonic disintegrator (MSE Sanyo Galtenkamp PLC, Belton Park, Loughborough, UK). Complete homogenization was confirmed with light microscopy. Following centrifugation at $2{ }^{\circ} \mathrm{C}$ for $45 \mathrm{~min}$ at $105000 \boldsymbol{g}$ (Optima TLX ultracentrifuge; Beckman Coulter Inc. Paulo Alto, CA, USA), the supernatant was collected, aliquoted and stored at $-80^{\circ} \mathrm{C}$. Protein content was determined using the bicinchoninic acid protein assay (Pierce, Rockford, IL, USA).

\section{Western blot analysis of GR protein}

A sample from each individual $(20 \mu \mathrm{g}$ total protein from hippocampus or hypothalamus) were mixed with $4 \times$ SDS sample buffer, boiled for $5 \mathrm{~min}$ and resolved by electrophoresis in 8\% SDS-PAGE) in Trisglycine (TG)-SDS buffer. Protein was electrophoretically transferred to polyvinylidene difluoride Western blotting membranes (Boehringer Mannheim, Mannheim, Germany) in TG-methanol buffer (overnight at $4{ }^{\circ} \mathrm{C}, 200 \mathrm{~mA}$ ) using a Bio-Rad trans-blot electrophoresis transfer cell (Hercules, CA, USA). The membranes were blocked for $1 \mathrm{~h}$ at room temperature (RT) with 5\% non-fat dry milk in Tris-buffered saline (TBS)-Tween (T), washed briefly in TBS-T and incubated for $1 \mathrm{~h}$ at RT in TBS-T with 1\% non-fat dry milk, containing the appropriate dilution of antibody (1:5000 monoclonal anti-actin (clone AC-40; Sigma) and 1:2000 polyclonal anti-GR (M-20; Santa Cruz Biotechnology, Santa Cruz, CA, USA)). Membranes were washed in TBS-T and placed in TBS-T with 1\% non-fat dry milk containing 1:2000 dilution of peroxidase-conjugated secondary anti-rabbit and anti-mouse antibody respectively (Amersham Life Sciences, Arlington Heights, IL, USA) for $1 \mathrm{~h}$ at RT. Blots were washed in TBS-T and visualized with Western blot chemi-luminescence reagent plus (NEN Life Science Products, Boston, MA, USA), exposed to ECL hyperfilm (Amersham Life Sciences) and quantified on the Fluor-S Multilmager using Quantity One software (Bio-Rad).

\section{Analytical methods}

Blood was collected in heparinized microtubes and centrifuged immediately in a microcentrifuge. Plasma concentration of glucose was enzymatically determined on a YSI 2700 SELECT biochemical analyzer (Yellow Springs Instrument, Yellow Springs, OH, USA). Plasma insulin and leptin were analyzed by radioimmunoassay (RIA) (rat insulin RIA kit and rat leptin RIA kit; Linco Research, St Charles, MO, USA). Progesterone and 17 $\beta$-estradiol were assayed with commercially available enzyme immunoassays (progesterone ELISA and estradiol ELISA; Biomar Diagnostic Systems, Marburg, Germany). Testosterone was measured with a solid-phase RIA (Coat-A-Count total 
testosterone; Diagnostic Products, Los Angeles, CA, USA). ACTH was determined by an immunoradiometric assay (IDS, Boldon, UK) and, for corticosterone measurement, an RIA was used (RSL 125I corticosterone RIA; ICN Biomedicals, Costa Mesa, CA, USA). Insulin collected during the clamp measurements was analyzed with a double-antibody RIA (Pharmacia, Uppsala, Sweden).

\section{Histochemical analyses}

Cryostat sections, $7 \mu \mathrm{m}$ thick, were prepared from the fresh frozen adrenals. The sections were fixed in $4 \%$ buffered formaldehyde, stained with hematoxylin and eosin, dehydrated and mounted.

\section{Statistical analysis}

All results are presented as means \pm S.E.M. The statistical method used for locomotion test and stress test was two-way analysis of variance (ANOVA). The area under the curve (AUC) was calculated using the trapezoidal rule and dividing by total time. Analysis of differences between groups was made with Student's $t$-test. All analyses were undertaken using the StatView software in the Macintosh system.

\section{Results}

There were no significant differences in birth weight between the rats designated for LPS treatment or control treatment $(6.30 \pm 0.12 \mathrm{~g}$ and $6.28 \pm 0.09 \mathrm{~g})$. Pups decapitated $30 \mathrm{~min}$ after LPS injection showed no significant changes in plasma corticosterone levels as compared with rats given a vehicle injection (10.5 $4.8 \mathrm{ng} / \mathrm{ml}, n=5$ and $15.7 \pm 5.6 \mathrm{ng} / \mathrm{ml}, n=5)$. However, pups decapitated $6 \mathrm{~h}$ after the LPS injection showed a higher plasma corticosterone concentration $(97.8 \pm 35.5 \mathrm{ng} / \mathrm{ml}, n=5)$ than did control rats, which had corticosterone levels below the detection limit of the assay $(n=5)$.

\section{Body weight and body composition}

At 5-11 weeks of age, there were no significant changes in body weight between LPS-treated rats and control rats (data not shown). Table 1 depicts total body weight and weights of various tissues in LPStreated and control rats at 11 weeks of age. The soleus and tibialis anterior muscles were significantly heavier in LPS-treated rats than in control rats $(P<0.05)$. The parametrial adipose tissue weighed significantly less $(P<0.05)$ and the adrenals were significantly heavier in the LPS-treated rats than in the control rats $(P<0.05)$.
Table 1 Total body weight $(\mathrm{g})$ and weights of extensor digitorum longus (EDL), soleus and tibialis anterior (TIB) muscles, parametrial, retroperitoneal and mesenteric adipose tissue, and adrenals, thymus, spleen and heart ( $\mathrm{g} / \mathrm{kg}$ body weight (bw)) in 11-week-old female LPS-treated and control rats. Data are means \pm S.E.M.; there were ten rats in each group.

\begin{tabular}{lll}
\hline & Control & LPS \\
\hline Total body weight $(\mathrm{g})$ & $210 \pm 4$ & $207 \pm 4$ \\
$\begin{array}{l}\text { Skeletal muscle }(\mathrm{g} / \mathrm{kg} \mathrm{bw}) \\
\quad \text { EDL }\end{array}$ & $0.37 \pm 0.02$ & $0.41 \pm 0.01$ \\
$\quad$ Soleus & $0.36 \pm 0.03$ & $0.45 \pm 0.03^{*}$ \\
$\quad$ TIB & $1.78 \pm 0.06$ & $2.07 \pm 0.09^{*}$ \\
Adipose tissue $(\mathrm{g} / \mathrm{kg} \mathrm{bw})$ & & \\
Parametrial & $22.4 \pm 1.5$ & $17.6 \pm 0.9^{*}$ \\
Retroperitoneal & $14.0 \pm 0.9$ & $12.9 \pm 1.0$ \\
$\quad$ Mesenteric & $12.1 \pm 0.7$ & $11.6 \pm 1.0$ \\
Other tissue $(\mathrm{g} / \mathrm{kg} \mathrm{bw})$ & & \\
$\quad$ Adrenals & $0.35 \pm 0.03$ & $0.44 \pm 0.02^{*}$ \\
$\quad$ Thymus & $2.10 \pm 0.13$ & $2.33 \pm 0.16$ \\
Spleen & $2.39 \pm 0.10$ & $2.22 \pm 0.12$ \\
Heart & $2.62 \pm 0.11$ & $2.82 \pm 0.06$ \\
\hline
\end{tabular}

${ }^{\star} P<0.05$

\section{Locomotion test}

Figure 1 shows the locomotor behavior of LPS-treated and control rats. The LPS-treated animals exhibited an initially $(0-15 \mathrm{~min})$ higher locomotor activity than did control rats. Two-way ANOVA showed a significant effect of treatment $(P<0.05)$ and also a significant effect of time $(P<0.001)$.

\section{Basal and stress-induced corticosterone secretion}

Figure 2A shows plasma corticosterone response to a novel environment stress test in 5-week-old, LPStreated and control rats. The ANOVA repeated measures showed that there was a significant effect of treatment and time on the stress-induced corticosterone secretion $(P<0.05)$. When comparing the groups at individual time-points, rats treated with LPS had significantly higher pre-stress levels of corticosterone than did control rats $(P<0.05)$. At 15,30 and $60 \mathrm{~min}$ after transfer to the new cage, the plasma corticosterone levels in the two groups did not differ. However, $90 \mathrm{~min}$ after exposure to stress, the LPStreated rats again had significantly higher corticosterone levels than did the control rats $(P<0.001)$. As shown in Fig. 2B, the average AUC of the corticosterone response to stress was significantly higher in LPStreated rats than in control rats $(P<0.05)$.

Table 2 shows the plasma corticosterone levels in response to stress, expressed as the difference between plasma corticosterone values and the basal plasma corticosterone. The LPS-treated rats had a lower stress response than did the control rats, i.e. the amplitude of the stress response was decreased. The 


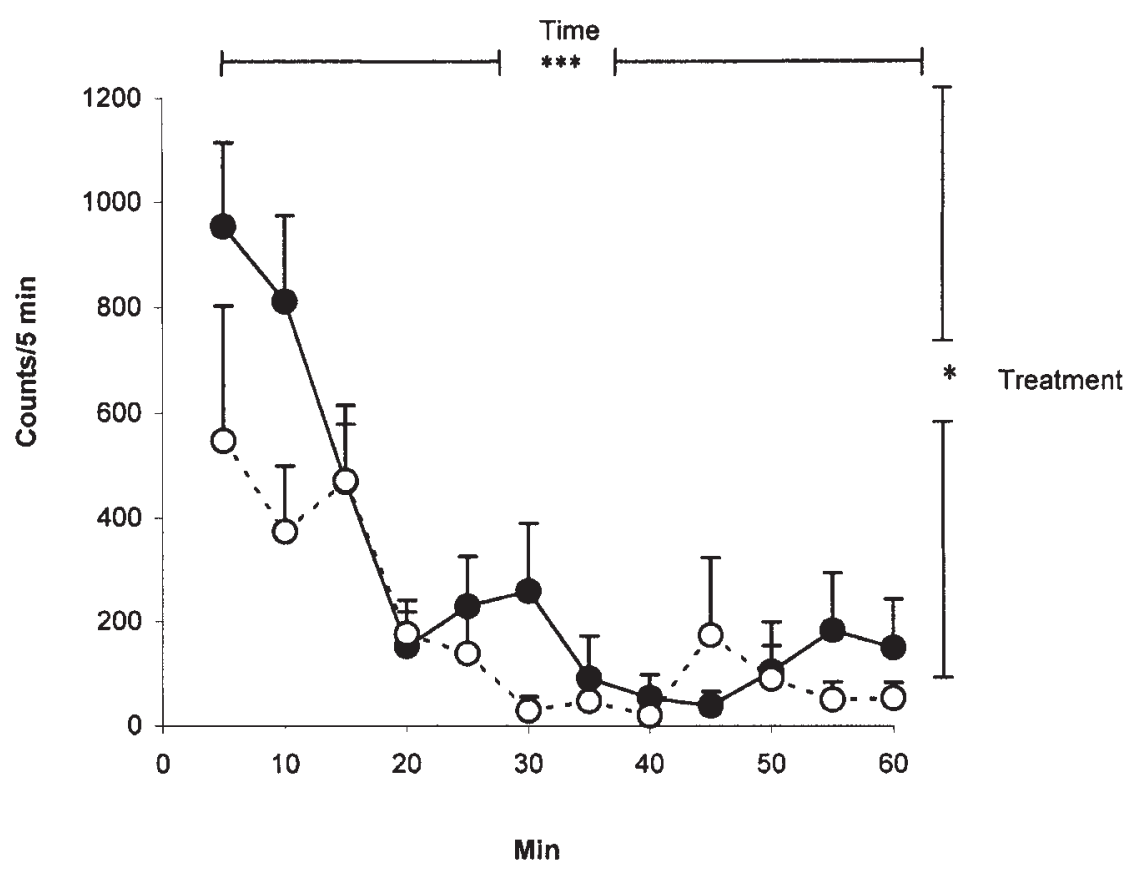

Figure 1 Locomotor activity (counts $/ 5 \mathrm{~min})$ in LPS-treated $(n=7 ; \bullet)$ and control rats $(n=7 ; 0)$. Data are presented as means \pm S.E.M. ${ }^{\star} P<0.05$ for treatment; ${ }^{* \star *} P<0.001$ for time (two-way ANOVA).

difference reached statistical significance at $30 \mathrm{~min}$ after transfer to the new cage $(P<0.05)$.

\section{Hemodynamic mesasurements}

There were no significant differences either in blood pressure or in heart rate between treated rats and control rats (data not shown).

\section{Hormonal analyses}

As shown in Table 3, fasting plasma concentration of progesterone was significantly lower in the LPS-treated group compared with controls. The testosterone levels tended to be elevated in LPS-exposed female rats, but failed to reach statistical significance. ACTH was significantly increased in the LPS-treated rats. The plasma concentrations of insulin and $17 \beta$-estradiol did not differ between LPS-treated animals and controls.

\section{Euglycemic hyperinsulinemic clamp (5 mU/kg per min)}

Figure 3 depicts the glucose infusion rate during the euglycemic hyperinsulinemic clamp in LPS-treated rats and control rats at 11 weeks of age. LPS-treated rats had a significantly higher glucose uptake during steady state $(60-200 \mathrm{~min})$ than control rats $(22.8 \pm$ $1.8 \mathrm{mg} / \mathrm{kg}$ per min and $18.2 \pm 1.3 \mathrm{mg} / \mathrm{kg}$ per min respectively, $P<0.05$ ). Mean plasma levels of glucose during steady state were $6.9 \pm 0.04 \mathrm{mmol} / \mathrm{l}$ in LPStreated rats and $7.0 \pm 0.03 \mathrm{mmol} / \mathrm{l}$ in control rats. The mean value of plasma insulin levels during steady state $(60-200 \mathrm{~min})$ revealed no significant difference between the groups $(91 \pm 6 \mathrm{mU} / \mathrm{l}$ and $94 \pm$ $12 \mathrm{mU} / \mathrm{l}$ in LPS-treated rats and controls respectively).

\section{GR protein expression in the brain}

As depicted in Fig. 4, rats exposed to LPS had significantly elevated levels of GR protein expression in the

Table 2 Plasma corticosterone response to a novel environment stress test, expressed as the difference between plasma corticosterone at 15, 30, 60 and 90 min and basal plasma corticosterone levels.

\begin{tabular}{|c|c|c|c|c|c|}
\hline & $\begin{array}{c}\text { Basal } 0 \text { min } \\
(\mathrm{ng} / \mathrm{ml})\end{array}$ & $\begin{array}{c}15 \mathrm{~min} \text {-basal } \\
(\mathrm{ng} / \mathrm{ml})\end{array}$ & $\underset{(\mathrm{ng} / \mathrm{ml})}{30 \mathrm{~min}-\text { basal }}$ & $\underset{(\mathrm{ng} / \mathrm{ml})}{60 \mathrm{~min}-\text { basal }}$ & $\underset{(\mathrm{ng} / \mathrm{ml})}{90 \underset{\mathrm{min}}{ }-\text { basal }}$ \\
\hline Control & $139.4 \pm 28.6$ & $622.9 \pm 116.8$ & $586.1 \pm 53.0$ & $347.9 \pm 99.0$ & $109.6 \pm 84.9$ \\
\hline LPS & $413.9 \pm 68.2^{*}$ & $370.8 \pm 71.6$ & $401.5 \pm 36.6^{*}$ & $269.6 \pm 79.0$ & $176.8 \pm 74.4$ \\
\hline
\end{tabular}

${ }^{*} P<0.05$, LPS-treated rats compared with control (Student's unpaired $t$-test). 

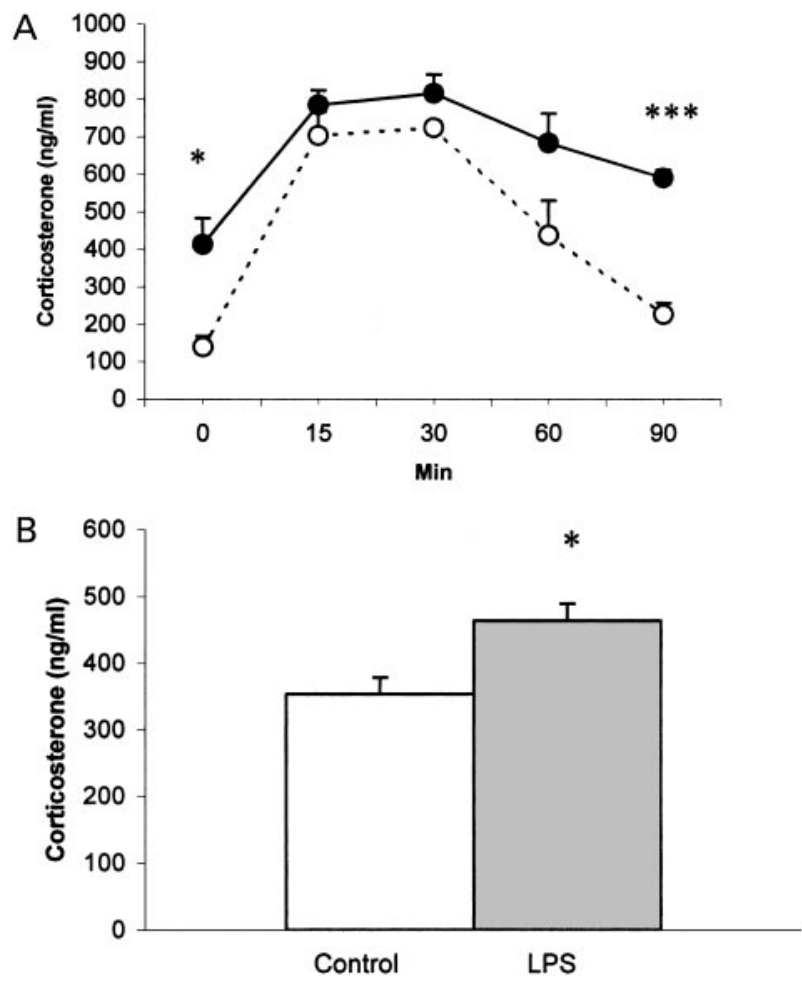

Figure 2 (A) Plasma corticosterone levels in 5-week-old, LPStreated $(n=8 ; \bullet)$ and control female rats $(n=5 ; 0)$ submitted to the novel environment stress test. Blood was sampled prior to ( $0 \mathrm{~min}$ ) and 15, 30, 60 and $90 \mathrm{~min}$ following exposure to stress. Data are presented as means \pm S.E.M. ${ }^{*} P<0.05,{ }^{* \star *} P<0.001$ (unpaired Student's $t$-test). (B) The corticosterone response to stress, expressed as AUC divided by total time. Data are presented as means \pm S.E.M. ${ }^{*} P<0.05$ (unpaired Student's $t$-test).

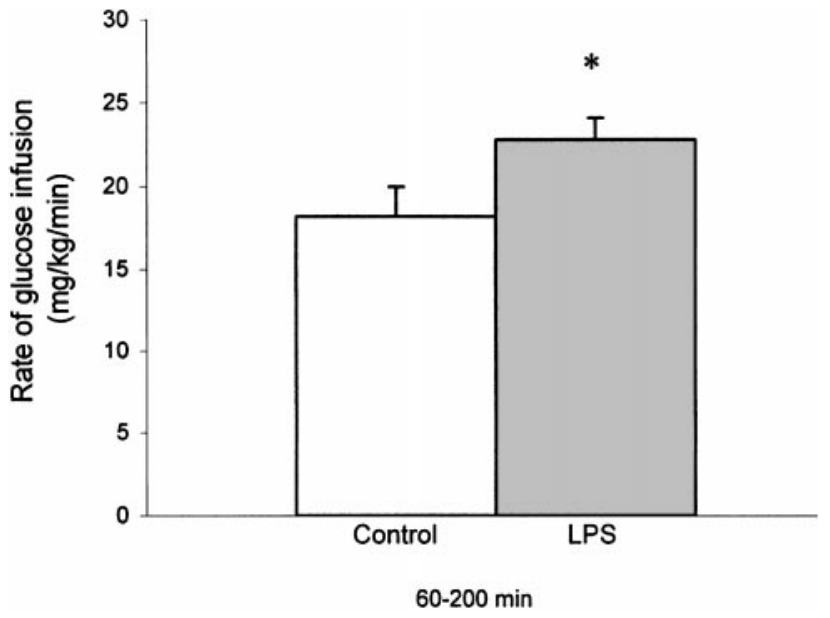

Figure 3 Glucose infusion rate at steady state $(60-200 \mathrm{~min})$ during the euglycemic hyperinsulinemic clamp ( $5 \mathrm{mU} / \mathrm{kg}$ per $\mathrm{min})$, performed on 11-week-old female, LPS-treated rats $(n=9$; shaded bar) and control rats ( $n=10$; open bar). Plasma glucose concentrations were $\sim 7 \mathrm{mmol} / \mathrm{l}$ in both groups. Data are presented as means \pm S.E.M. ${ }^{*} P<0.05$ (unpaired Student's $t$-test).
Table 3 Fasting plasma levels of $17 \beta$-estradiol ( 9 weeks), insulin (7 weeks), ACTH (8 weeks), testosterone (9 weeks) and progesterone (9 weeks) in LPS-treated and control rats. Data are means \pm S.E.M.; there were ten rats in each group.

\begin{tabular}{lcc}
\hline & Control & LPS \\
\hline Progesterone $(\mathrm{nmol} / \mathrm{l})$ & $92.7 \pm 8.3$ & $66.0 \pm 6.7^{*}$ \\
ACTH $(\mathrm{pg} / \mathrm{ml})$ & $9.5 \pm 2.0$ & $19.1 \pm 3.1^{*}$ \\
Testosterone $(\mathrm{nmol} / \mathrm{l})$ & $0.24 \pm 0.02$ & $0.44 \pm 0.10$ \\
$17 \beta$-estradiol $(\mathrm{pmol} / \mathrm{l})$ & $120 \pm 9.3$ & $106 \pm 8.0$ \\
Insulin $(\mathrm{mU} / \mathrm{l})$ & $5.7 \pm 0.8$ & $5.1 \pm 0.5$ \\
\hline
\end{tabular}

${ }^{\star} P<0.05$.

hypothalamus, expressed as a ratio of GR to actin, to adjust for unequal loading of the lanes $(0.54 \pm 0.08$ and $0.25 \pm 0.08$ in LPS-treated rats $(n=8)$ and control rats $(n=5)$ respectively, $P<0.05)$. In the hippocampus, there were no significant differences in GR protein expression $(1.18 \pm 0.22$ for LPS-treated rats $(n=8)$ and $0.95 \pm 0.11$ for controls $(n=5))$.

\section{Histochemical analyses}

Adrenal sections from 11-week-old control and LPStreated rats are shown in Fig. 5A and B. In the LPStreated rats, the inner part of the zona fasciculata of the adrenal cortex appeared to be affected (Fig. 5B and C). This part of the cortex appeared to be enlarged, mainly due to the increased volume of the sinusoids. These changes were pronounced in four out of ten LPS-treated animals, and of lesser magnitude in two animals. In the remaining four animals, these changes were not seen.

\section{Discussion}

Exposure of 3-day-old female pups to endotoxin was followed by a pronounced elevation of plasma corticosterone levels $6 \mathrm{~h}$ after injection. This is the expected consequence of endotoxin at the dose used in this study, which is known to stimulate the HPA axis, also during the stress hyporesponsive period $(21,22)$. In the adult female rat, the postnatal endotoxin exposure was followed by an increased sensitivity to insulin. Locomotor activity and muscle mass were increased in LPS-treated rats. The HPG axis was affected, leading to decreased circulating progesterone and a tendency to increased circulating testosterone. The results of this study also showed that postnatal exposure to endotoxin resulted in long-term changes in the HPA axis.

LPS-treated rats had higher non-fasting, pre-stress levels of corticosterone than did control rats. In accordance with this, Shanks and co-workers (12) showed that early postnatal exposure to endotoxin resulted in increased basal corticosterone levels over a 24 -h cycle 


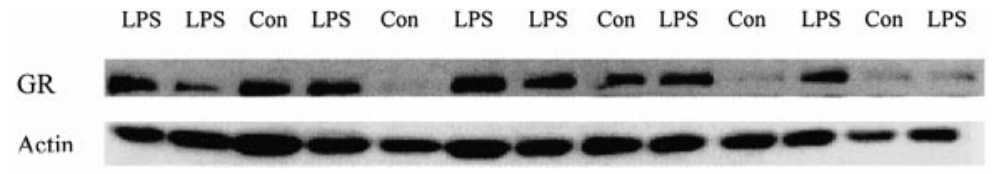

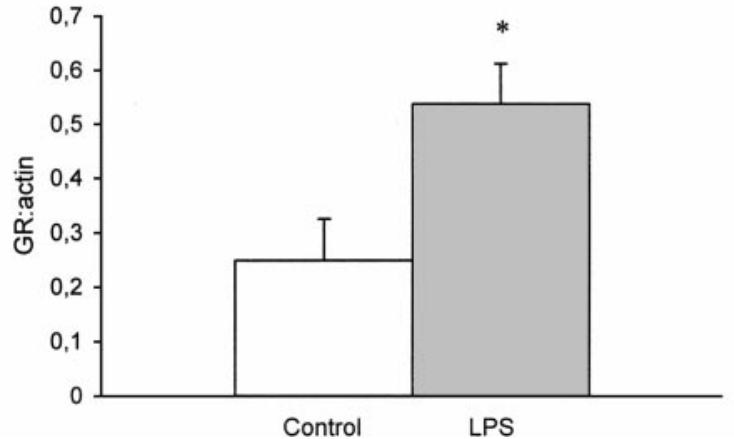

in the adult rat. Both an increased number of corticosterone secretion pulses and increased pulse amplitudes were seen (12). Adrenal weight was significantly increased in our LPS-treated rats at 11 weeks of age. Histochemical analyses showed that the adrenals were morphologically changed as compared with the adrenals from control rats. The inner part of the zona fasciculata of the adrenal cortex appeared to be affected, mainly due to an increased volume of the blood vessels of the adrenals, the sinusoids. The morphological picture is suggestive of a chronic ACTH stimulation (23). This is in accordance with the increased basal ACTH and corticosterone levels seen in LPS-treated rats.

When exposing the animals to a novel environment stress, the corticosterone response to stress expressed as AUC was significantly higher in LPS-treated rats than in control rats. However, when considering the difference between plasma corticosterone during stress and basal levels, the LPS-treated rats showed a reduction in amplitude of the stress response as compared with control rats. The feedback control of the HPA axis following stress is regulated by centrally located GRs. In this study, an elevation of GR protein was seen in the hypothalamus, but not in the hippocampus. In a previous study, Shanks and co-workers (11) observed that postnatal endotoxin exposure resulted in increased HPA activity in response to stress. Furthermore, they reported GR receptor reduction in the hippocampus and frontal cortex, but no statistically significant reduction in hypothalamic regions (11). Explanations for this discrepancy may be that they used rats of the Long-Evans strain, whereas we used Wistar rats. Rat strain and genetic background are factors known to influence variability in HPA axis response to stress $(24,25)$. Furthermore, animals in that study were older by the time of examination than were the animals in our study, restraint stress was used instead of a novel environment stress and GR protein was studied by receptor binding instead of Western blot.

In agreement with the reduction in stress response amplitude reported in the present study, a reduced corticosterone response to stress was also seen after postnatal interleukin-1 $\beta$ administration (26). Interleukin-1 $\beta$ is one of the cytokines released after LPS exposure (27). Plagemann et al. (26) also report a permanent disorganization of the parvocellular neurons after postnatal cytokine exposure. An impact of LPS, possibly mediated through cytokines, on the development of these neurons may explain the effects on the HPA axis seen in this study.

Activation of the HPA axis is well known to have an inhibitory effect on the HPG axis (28). In this study, the HPG axis was also affected in the adult animals after postnatal endotoxin exposure, showing decreased circulating progesterone and increased testosterone levels, although this was not significant. The inhibitory effect of increased HPA axis activity on the HPG axis may explain the low circulating progesterone levels in LPS-treated rats. Increased testosterone levels in female rats were also seen after prenatal exposure to endotoxin or cytokines $(14,15)$. In adult animals, endotoxin is known to inhibit the HPG axis both at the level of the brain and the gonads and it is suggested that this effect is mediated through interleukin-1 (27). The elevated testosterone levels may also be of adrenal origin, since an adrenal hypertrophy suggestive of overstimulation was found and basal ACTH and corticosterone levels were increased. However, it is still controversial as to whether or not rat adrenals have the capacity to secrete androgens $(29,30)$. 
(A)

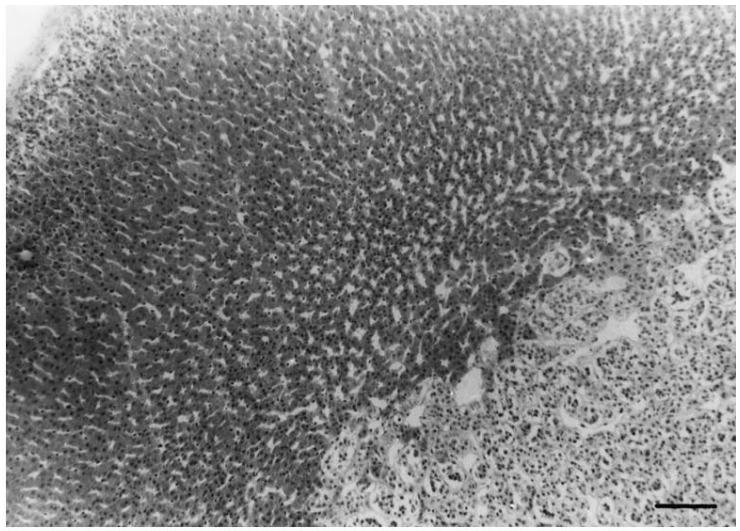

(B)

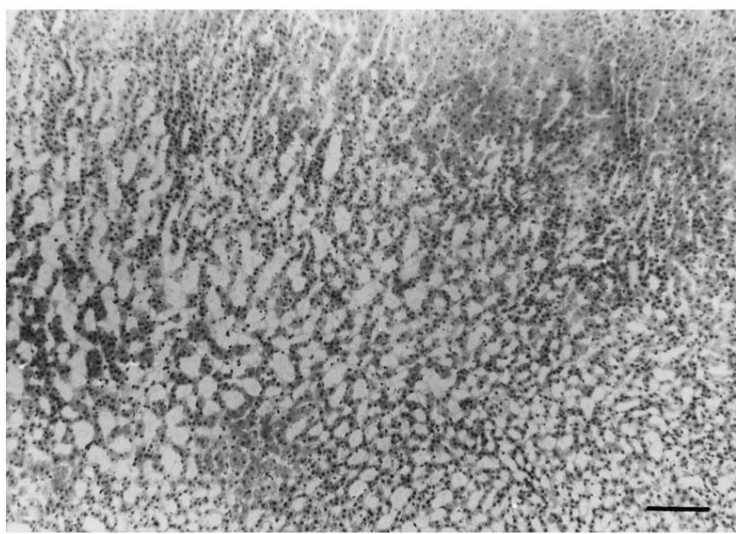

(C)

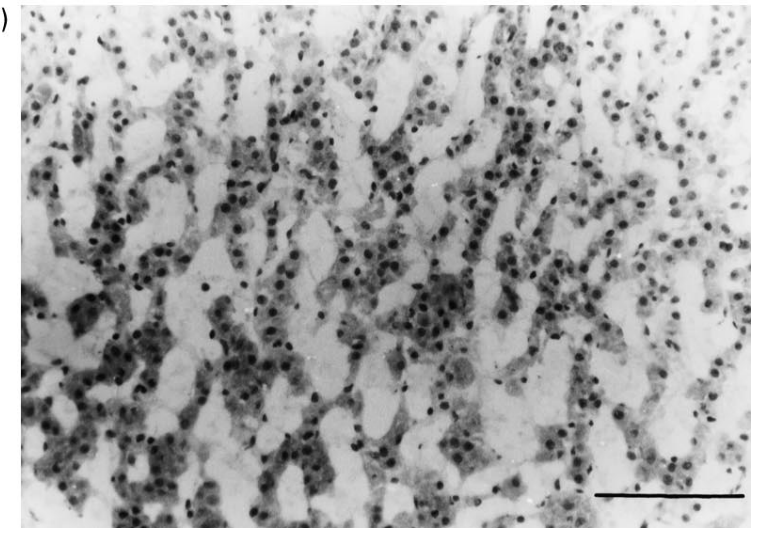

Figure $\mathbf{5}$ Sections from the adrenals. (A) Adrenal section from a control rat. (B) Adrenal section from an LPS-treated rat. There is a marked distension of the sinusoids in the inner layer of the zona fasciculata and zona reticularis. (C) Magnification of (B) showing the enlarged sinusoids. Hematoxylin/eosin. Bar $=100 \mu \mathrm{m}$.

The increase in muscle weight and the slight reduction in fat depots seen in LPS-treated rats at 11 weeks of age may be explained by increased testosterone levels, well known to have anabolic effects on muscle. However, the changes in body composition may also be caused by an increased general motor activity in LPS-exposed animals compared with controls, since exercise is known to increase relative lean body mass and decrease fat mass (31). Neonatal glucocorticoid exposure has long-term effects on general motor activity and novelty induced ambulation (3). It has also been shown previously that immune activation with cytokines during development results in increased general motor activity (32), which is well in line with the increase in exploratory behavior observed in LPS-treated rats in the present study. It may be that the immunostimulated increase in the HPA axis activity seen in the LPS-exposed pups programmed an increased general motor activity, explaining the muscle enlargement.

At 11 weeks of age, a significant increase in glucose infusion rate during the euglycemic hyperinsulinemic clamp at $5 \mathrm{mU} / \mathrm{kg}$ per min was observed in the LPStreated rats. Skeletal muscles are important targets for insulin, since they are the major insulin-dependent peripheral tissue in the body. They represent $40-50 \%$ of total body weight and contribute to $35 \%$ of glucose uptake in response to an intravenous glucose injection (33). Increased muscle weight and decreased fat depot weight probably contribute to the increased sensitivity to insulin and increased muscle glucose uptake in LPS-treated rats. Increased physical activity is a powerful inducer of increased insulin sensitivity $(34,35)$ and may be a contributing factor to the increased insulin sensitivity seen after postnatal LPS exposure. The results show that an enhanced HPA activity is not always accompanied by obesity and insulin resistance (13), but can co-exist with a reduction in the amount of fat tissue and an increase in insulin sensitivity.

In a follow-up study, we examined the effects of postnatal corticosterone exposure on insulin sensitivity and HPA axis regulation, and found that it also resulted in increased insulin sensitivity, but had other effects on HPA axis regulation (authors', unpublished observations). Hence, it is suggested that some effects of the endotoxin exposure seen in this study might be glucocorticoid mediated. However, the glucocorticoid exposures in the two studies are probably quantitatively and qualitatively discordant, leading to somewhat different long-lasting consequences. Contrary to our findings of increased insulin sensitivity after LPS or corticosterone exposure, Nyirenda and co-workers (36) observed that prenatal exposure to dexamethasone, a synthetic glucocorticoid, resulted in impaired glucose tolerance in the adult offspring. However, when administering dexamethasone postnatally, no effects of dexamethasone were seen on adult glucose tolerance, as measured by an oral glucose tolerance test (37).

Clinical studies have shown that the perinatal environment is important in predicting adult somatic health $(1,2)$. The present work has demonstrated that postnatal exposure to endotoxin can induce changes in body composition, insulin sensitivity and neuroendocrine function in the adult female rat. To 
further elucidate the mechanisms involved, additional studies are required.

\section{Acknowledgements}

The laboratory assistance of Britt-Mari Larsson and Inger Oscarsson is gratefully acknowledged. This study was supported by grants from the Swedish Medical Research Council (project No. 12206, No. 8668), Knut and Alice Wallenberg Foundation, Astra Arcus, the Magnus Bergwall Foundation, the Novo Nordisk Foundation and the Swedish Heart and Lung Foundation.

\section{References}

1 Barker DJ, Hales CN, Fall CH, Osmond C, Phipps K \& Clark PM. Type 2 (non-insulin-dependent) diabetes mellitus, hypertension and hyperlipidaemia (syndrome $\mathrm{X}$ ): relation to reduced fetal growth. Diabetologia $19933662-67$.

2 Valdez R, Athens MA, Thompson GH, Bradshaw BS \& Stern MP. Birthweight and adult health outcomes in a biethnic population in the USA. Diabetologia 199437 624-631.

3 De Kloet ER, Rosenfeld P, Van Eekelen JA, Sutanto W \& Levine S. Stress, glucocorticoids and development. Progress in Brain Research 198873 101-120.

4 Sapolsky RM \& Meaney MJ. Maturation of the adrenocortical stress response: neuroendocrine control mechanisms and the stress hyporesponsive period. Brain Research 1986396 64-76.

5 Bohn M. Glucocorticoid induced teratologies of the nervous system. In Neurobehavioral Teratology, pp 365-387. Ed. J Yanai. New York: Elsevier, 1984.

6 Ardeleanu A \& Sterescu N. RNA and DNA synthesis in developing rat brain: hormonal influences. Psychoneuroendocrinology 19783 93-101.

7 Balazs R \& Cotterrell M. Effect of hormonal state on cell number and functional maturation of the brain. Nature 1972236 348-350.

8 Meaney MJ. Diorio J. Francis D, Widdowson J, LaPlante P, Caldji C et al. Early environmental regulation of forebrain glucocorticoid receptor gene expression: implications for adrenocortical responses to stress. Developmental Neuroscience 1996 18 49-72.

9 Plotsky PM \& Meaney MJ. Early, postnatal experience alters hypothalamic corticotropin-releasing factor (CRF) mRNA, median eminence CRF content and stress-induced release in adult rats. Brain Research Molecular Brain Reseach 199318 195-200.

10 Witek-Janusek L. Pituitary-adrenal response to bacterial endotoxin in developing rats. American Journal of Physiology 1988 255 E525-E530.

11 Shanks N, Larocque S \& Meaney MJ. Neonatal endotoxin exposure alters the development of the hypothalamic-pituitary-adrenal axis: early illness and later responsivity to stress. Journal of Neuroscience 199515 376-384.

12 Shanks N, Windle RJ, Perks PA, Harbuz MS, Jessop DS, Ingram CD et al. Early-life exposure to endotoxin alters hypothalamic-pituitary-adrenal function and predisposition to inflammation. PNAS 200097 5645-5650.

13 Bjorntorp P. Neuroendocrine perturbations as a cause of insulin resistance. Diabetes/Metabolism Reviews 199915 427-441.

14 Nilsson C, Larsson BM, Jennische E, Eriksson E, Bjorntorp P, York DA et al. Maternal endotoxemia results in obesity and insulin resistance in adult male offspring. Endocrinology $2001 \mathbf{1 4 2}$ 2622-2630.

15 Dahlgren J, Nilsson C, Jennische E, Ho H-P, Eriksson E, Niklasson A et al. Prenatal cytokine exposure results in obesity, and genderspecific programming of neuroendocrine axes in adult rats. American Journal of Physiology 2001281 326-334.
16 Smith MS, Freeman ME \& Neill JD. The control of progesterone secretion during the estrous cycle and early pseudopregnancy in the rat: prolactin, gonadotropin and steroid levels associated with rescue of the corpus luteum of pseudopregnancy. Endocrinology $197596219-226$.

17 Ericson E, Samuelsson J \& Ahlenius S. Photocell measurements of rat motor activity. A contribution to sensitivity and variation in behavioral observations. Journal of Pharmacological Methods $199125111-122$.

18 Lahti RA \& Barsuhn C. The effect of minor tranquilizers on stressinduced increases in rat plasma corticosteroids. Psychopharmacologia $197435215-220$.

19 Bunag RD. Validation in awake rats of a tail-cuff method for measuring systolic pressure. Journal of Applied Physiology 1973 $34279-282$.

20 Holmang A, Svedberg J, Jennische E \& Bjorntorp P. Effects of testosterone on muscle insulin sensitivity and morphology in female rats (published erratum appears in American Journal of Physiology 1993 264: section E following table of contents). American Journal of Physiology 1990259 E555-E560.

21 Shanks N \& Meaney MJ. Hypothalamic-pituitary-adrenal activation following endotoxin administration in the developing rat: a CRH-mediated effect. Journal of Neuroendocrinology 19946 375-383.

22 Dent GW, Smith MA \& Levine S. The ontogeny of the neuroendocrine response to endotoxin. Brain Research Development Brain Research 1999117 21-29.

23 Pudney J, Price GM, Whitehouse BJ \& Vinson GP. Effects of chronic ACTH stimulation on the morphology of the rat adrenal cortex. Anatomical Record 1984210 603-615.

24 Windle RJ, Wood SA, Lightman SL \& Ingram CD. The pulsatile characteristics of hypothalamo-pituitary-adrenal activity in female Lewis and Fischer 344 rats and its relationship to differential stress responses. Endocrinology 1998139 4044-4052.

25 Shanks N, Griffiths J, Zalcman S, Zacharko RM \& Anisman H. Mouse strain differences in plasma corticosterone following uncontrollable footshock. Pharmacology Biochemistry and Behavior $199036515-519$.

26 Plagemann A, Staudt A, Gotz F, Malz U, Rohde W, Rake A et al. Long-term effects of early postnatally administered interleukin1-beta on the hypothalamic-pituitary-adrenal (HPA) axis in rats. Endocrine Regulations $19983277-85$.

27 Rivier C. Role of endotoxin and interleukin-1 in modulating ACTH, LH and sex steroid secretion. Advances in Experimental Medicine and Biology 1990274 295-301.

28 Chrousos GP, Torpy DJ \& Gold PW. Interactions between the hypothalamic-pituitary-adrenal axis and the female reproductive system: clinical implications. Annals of Internal Medicine 1998 $129229-240$.

29 Belanger B, Couture J, Caron S, Bodou P, Fiet J \& Belanger A. Production and secretion of C-19 steroids by rat and guinea pig adrenals. Steroids $1990 \mathbf{5 5}$ 360-365.

30 van Weerden WM, Bierings HG, van Steenbrugge GJ, de Jong FH \& Schroder FH. Adrenal glands of mouse and rat do not synthesize androgens. Life Sciences 199250 857-861.

31 Hickson RC, Heusner WW, Huss WD, Jackson DE, Anderson DA, Jones DA et al. Effects of dianabol and high-intensity sprint training on body composition of rats. Medicine and Science in Sports and Exercise 19768 191-195.

32 Gotz F, Dorner G, Malz U, Rohde W, Stahl F, Poppe I et al. Shortand long-term effects of perinatal interleukin-1 beta-application in rats. Neuroendocrinology $1993 \mathbf{5 8} 344-351$.

33 Curtis-Prior PB, Trethewey J, Stewart GA \& Hanley T. The contribution of different organs and tissues of the rat to assimilation of glucose. Diabetologia $19695384-391$.

34 Richter EA, Garetto LP, Goodman MN \& Ruderman NB. Muscle glucose metabolism following exercise in the rat: increased sensitivity to insulin. Journal of Clinical Investigation 198269 785-793.

35 Niklasson M, Daneryd P, Lonnroth P \& Holmang A. Effects of exercise on insulin distribution and action in testosterone-treated 
oophorectomized female rats. Journal of Applied Physiology 2000 $882116-2122$.

36 Nyirenda MJ, Lindsay RS, Kenyon CJ, Burchell A \& Seckl JR. Glucocorticoid exposure in late gestation permanently programs rat hepatic phosphoenolpyruvate carboxykinase and glucocorticoid receptor expression and causes glucose intolerance in adult offspring. Journal of Clinical Investigation $1998 \quad 101$ $2174-2181$
37 Nyirenda MJ, Welberg LA \& Seckl JR. Programming hyperglycaemia in the rat through prenatal exposure to glucocorticoids fetal effect or maternal influence? Journal of Endocrinology 2001 $170653-660$.

Received 1 August 2001

Accepted 9 October 2001 